\title{
Os desafios teórico-metodológicos do Ensino de Sociologia no Ensino Médio
}

Amurabi Oliveira*

\section{Resumo}

Com o processo de reintrodução da Sociologia na Educação Básica em 2008, muito tem se debatido sobre o Ensino desta ciência nas escolas. No entanto, devido à própria ausência de uma tradição da Sociologia no currículo escolar, a discussão ainda é incipiente e restrita a uma pequena comunidade de pesquisadores. Uma das questôes relevantes que emergem ante a esse novo cenário é sobre quais os desafios para a prática docente do professor de Sociologia, nesse sentido, visa-se contribuir para essa discussão por meio de uma reflexão articulada em dois níveis: o primeiro remete aos desafios teóricos, o segundo aos desafios metodológicos do Ensino de Sociologia. Para tanto, recorre-se principalmente à obra de Giddens para compreender a relaçáo entre o conhecimento sociológico e o senso comum, questão, que em nosso entender, mostrase de suma relevância para o Ensino da Sociologia na realidade escolar. Neste trabalho chama-se a atenção para o fato de que a proximidade com o senso comum abre um campo de possibilidades, mas também se constitui como um desafio para o docente, considerando a "dupla hermenêutica" da Sociologia, o que se apresenta tanto no nível teórico quanto metodológico.

Palavras-chave: Ensino de Sociologia. Prática Docente. Metodologia do Ensino.

* Doutor em Sociologia pela Universidade Federal de Pernambuco (UFPE). Professor do Departamento de Sociologia e Ciência Política e do Programa de Pós-Graduação em Sociologia Política da Universidade Federal de Santa Catarina (UFSC). 


\section{A Sociologia e o seu Ensino: questões preliminares}

Muito tem sido debatido nos últimos tempos em torno do retorno da Sociologia ao currículo do Ensino Médio em nível nacional ${ }^{1}$, contudo, devido à própria incipiência do debate, uma vez que ainda náo foi formada uma comunidade de pesquisadores em torno da questáo (SOUZA, 2008), persistem problemáticas que demandam maior cuidado por parte dos pesquisadores na área, em especial no que tange aos desafios que necessitam ser enfrentados pelo ensino desta ciência na Educação Básica ${ }^{2}$. Centrar-nos-emos, neste artigo, nas questóes relacionadas aos desafios teóricos e metodológicos postos ao Ensino de Sociologia, que se devem tanto a aspectos ontológicos da própria ciência social quanto a aspectos contingenciais, que dizem respeitos às condiçôes objetivas em que este ensino é realizado, partindo principalmente das contribuiçóes das teorias sociológicas contemporâneas, com destaque para as formulaçôes do sociólogo britânico Anthony Giddens.

Devemos considerar que lei no $11.684 / 2008$ (BRASIL, 2008), que reintroduziu a Sociologia no Ensino Médio, fomentou um cenário que já vinha se delineando a partir dos anos 1990, de incremento na pesquisa em torno desta temática, bem como de expansão dos cursos de Licenciatura em Ciências Sociais, o que pode ser percebido através do aumento contínuo de pesquisas desenvolvidas em nível de pósgraduaçáo acerca do Ensino de Sociologia (SILVA, 2010; HANDFAS, 2011; CAREGNATO; CORDEIRO, 2014), e da ampliação de temáticas exploradas (OLIVEIRA, 2014). Contudo, ainda que outros autores tenham delineado o histórico da Sociologia enquanto disciplina escolar ${ }^{3}$, acreditamos que seja interessante realizar breves apontamentos em torno do percurso da Sociologia na escola.

Conforme apontam as próprias Orientaçóes Curriculares Nacionais de Sociologia (OCN) (BRASIL, 2006), a ideia da introdução da disciplina na educaçáo básica se dá ainda no século XIX, por sugestáo de Rui Barbosa no debate em torno da reforma educacional em 1882, contudo, apenas no século XX que este anseio intelectual se concretiza ${ }^{4}$. Podemos mesmo apontar que no século XIX temos um ensino de Ciências Sociais, se incluirmos nesse campo a Antropologia, a Ciência Política, a Economia, o Direito, a História, a Geografia, a Psicologia, a Estatística e a própria Sociologia (SILVA, 2010), ainda que quando nos refiramos aqui ao ensino não estamos necessariamente relacionando-o a uma disciplina específica, aliás, devemos destacar que surgimento de Sociologia no Brasil se articula visceralmente ao Direito e ao positivismo (CÂNDIDO, 2006), não à toa, os primeiros manuais de Sociologia são escritos por juristas (MEUCCI, 2011). 
Todavia, é a partir dos anos de 1920 que temos um processo de institucionalização e sistematização da Sociologia, destaca-se o fato que em 1925 temos a reforma educacional promovida por João Luiz Alves-Rocha Vaz que introduziu a Sociologia no currículo da Escola Normal e da Secundária, o que levou a uma profusão de Manuais de Sociologia, em especial aqueles voltados para os cursos de formação de professores, contando com a elaboraçáo destes por parte de intelectuais renomados como Fernando de Azevedo, Delgado de Carvalho, Alceu Amoroso Lima, Amaral Fontoura, Gilberto Freyre, dentre outros. Temos ainda que, na reforma promovida por Francisco Campos, em 1931, a Sociologia é introduzida nos cursos complementares, preparatórios para o ingresso nas Faculdades de Direito, de Ciências Médicas e de Arquitetura e Engenharia ${ }^{5}$.

Percebemos, portanto, que o período entre as décadas de 1920 e 1940 são considerados os "anos dourados" da referida disciplina (RIBEIRO et al., 2009), em que há um profícuo debate intelectual em torno da Sociologia. Sendo assim, para Meucci (2011, p. 57):

Os manuais didáticos de Sociologia publicados na década de 1930 confirmam, com efeito, a nossa hipótese de que o conhecimento sociológico foi compreendido como uma área de conhecimento dedicada à renovaçáo da vida intelectual, à substituição do ensaísmo jurídico e literário pelo realismo científico.

Nesse momento, o realismo científico que a Sociologia seria capaz de promover teria condiçôes de fomentar uma renovação intelectual dentro do currículo da Escola Secundária. Náo podemos nos olvidar que na década de 1930 o campo educacional passava por um intenso debate, marcado pelo Manifesto dos Pioneiros da Educação Nova, de 1932, no qual defendiam a introdução de métodos científicos para o desenvolvimento da prática educativa, em contraposição ao "empirismo" que vinha sendo praticado pela denominada pedagogia tradicional, o que, para Saviani (2009), representa um aspecto extremamente conservador com relação ao movimento, uma vez que desloca o debate do âmbito político para o técnico. Vale destacar que um dos líderes intelectuais era justamente Fernando Azevedo, que se encontrava fortemente influenciado tanto por Dewey quanto por Durkheim; sendo um dos principais difusores das ideias deste sociólogo francês no Brasil.

Este é um período que há, portanto, a elaboração de um projeto político do país que articulava os ideais da ciência, modernidade e educaçáo (SARANDY, 2004), e a Sociologia encontrava-se, assim, articulada a este projeto, representando um processo 
de modernização, ainda que devamos chamar atenção para o fato, que nos aponta Canclini (1997), acerca da existência nos países latino-americanos, em especial na primeira metade do século XX, de um modernismo sem modernizaçáo, o que significa a perduração das estruturas arcaicas de dominação e exploração na sociedade brasileira, a manutenção da cultura patrimonialista aqui existente (FAORO, 2001).

Esses "anos dourados" foram abalados ante a Reforma Capanema, de 1942, que retira a Sociologia dos Cursos Secundários, exceto no curso normal ${ }^{6}$. As reformas educacionais levadas a cabo pelo governo de exceção, instaurado pela ditadura militar em 1964, mostram-se na forma de um golpe ainda mais duro para o Ensino de Sociologia neste cenário, e para as disciplinas humanísticas como um todo (SILVA, 2007), pois, através da Lei 5.692/1971 (BRASIL, 1971) houve um processo de "profissionalização" do currículo escolar, ao mesmo tempo em que foram criadas novas disciplinas obrigatórias: Educação Moral e Cívica e Organização Social e Política Brasileira (OSPB). Entretanto, seria uma visão simplista interpretar as presenças e as ausências da Sociologia no currículo escolar como um simples reflexo dos regimes políticos, não podemos esquecer, por exemplo, que a elaboração da primeira Lei de Diretrizes e Bases da Educação, em 1961, deu-se em um período democrático, mas que, no entanto, não houve qualquer mençáo à reintrodução desta disciplina (MORAES, 2011).

Ante o processo de redemocratização da sociedade brasileira a Sociologia passa a vislumbrar a possibilidade de reingresso na escola, contudo, as iniciativas ainda se davam de forma pontual e desarticulada entre os Estados da Federação. Em 2001 houve o ensejo através da aprovação da reintroduçáo da Sociologia e Filosofia nos currículos, contudo, a lei que substancializaria tal iniciativa foi vetada, no mesmo ano, pelo entáo presidente Fernando Henrique Cardoso, ironicamente sociólogo 7 .

Apenas em 2006, por meio do parecer $\mathrm{n}^{\circ} 38$, do Conselho Nacional de Educação (CNE), é que a Sociologia passa a ser incluída nos currículos da Educação Básica, o que toma força de lei em 2008, através da Lei no 11.648 (BRASIL, 2008). A reconstituição histórica desse campo, ainda que de forma sintética, faz-se necessária para que compreendamos de que cenário institucional estamos falando, e em que conjuntura a Sociologia vem sendo implementada nas escolas. O que podemos perceber é que apenas no período entre 1925 e 1942 é que a Sociologia encontrou-se de forma estável na Educação Básica (GEULFI, 2001), o que implicou numa ausência de tradição escolar desta disciplina, e das próprias discussóes envolvendo a dimensão teórica e metodológica da mesma no universo da escola.

Antes de adentrarmos no foco desse artigo, que é a problematização em torno dos desafios teóricos e metodológicos posto ao Ensino de Sociologia na Educação 
Básica a partir da teoria contemporânea, especialmente do substrato elaborado por Giddens, cabe-nos aqui realizar uma breve reflexão em torno da contribuição dos clássicos para essa discussão, ainda que esse não seja o nosso foco nesse trabalho.

\section{Contribuições dos clássicos para o Ensino de Sociologia}

Para iniciarmos nossa reflexão, faz-se pertinente a discussão elaborada por Alexander (1999) acerca da relevância dos clássicos na Sociologia, indicando que eles gozam de um status privilegiado em face da exploraçáo contemporânea no mesmo campo, estabelecendo critérios básicos em sua especialidade. De modo inverso ao das Ciências Naturais, cuja lógica de produção do conhecimento se dá através da superação de paradigmas, nas Ciências Sociais o que ocorreria seria um acúmulo de paradigmas, o que possibilitaria a existência de autores clássicos. Ainda segundo o autor:

Para mim é possível adquirir conhecimento cumulativo autêntico sobre o mundo a partir de pontos de vista diferentes e opostos - e mesmo sustentar leis explicativas relativamente antecipatórias a partir de orientações gerais que difiram em substância. Afirmo apenas que as condiçôes da ciência social tornam altamente improvável o consenso sobre a natureza exata do conhecimento empírico - para náo falar do consenso sobre leis explicativas. Em ciência social, portanto, os argumentos a respeito da verdade científica não se referem apenas ao nível empírico; eles atravessam o leque total de empreendimentos não-empíricos que amparam pontos de vista concorrentes. (ALEXANDER, 1999, p. 36).

Essas questôes apontam para a relevância de recorrermos a estes autores para pensarmos os dilemas nos quais estáo envolvidos a Sociologia na Educação Básica. Do ponto de vista teórico Karl Marx, Émile Durkheim e Max Weber, possuem diferenças substanciais, mas que não inviabiliza a elaboração de uma reflexão sobre as pertinências das questôes lançadas pelos três. Para essa discussão, é necessário levar em consideração o que é apontado por Barbosa, Quintaneiro e Riveiro (2012, p. 30):

As teorias de Karl Marx (1818-1883), Émile Durkheim (18581917) e Max weber (1864-1920), assim como refletem os problemas de seu tempo, visam a fornecer uma explicaçáo racional e objetiva das causas responsáveis, em todas as épocas, pela formação, transformação ou eventual desintegração dos grupos humanos e das instituiçóes. Por isso, o pensamento 
desses autores continua sendo relevante para entender nossas sociedades e seus conflitos, e esse é o motivo pelo qual são considerados os clássicos da sociologia.

Como as contribuições teóricas dos clássicos são assumidas de forma tácita pelo "cientista social médio" (ALEXANDER, 1999), o que pode ser atestado pela presença constante destes nas diretrizes curriculares estaduais para o Ensino de Sociologia, conforme nos indica a pesquisa realizada por Santos (2012), centraremos aqui o desenvolvimento de uma reflexão em torno das contribuiçôes metodológicas desses autores, ainda que compreendamos que teoria e método não são instâncias dissociadas.

$\mathrm{Na}$ esteira do pensamento hegeliano (VANDENBERGUE, 2012), Marx (2008, p. 1080) parte de uma compreensão de que há uma diferença substancial entre a essência e a aparência das coisas, de tal modo que "[...] toda ciência seria supérflua se houvesse coincidência imediata entre a aparência e a essência das coisas [...]”. Nesse sentido, a compreensão de produção do conhecimento em Marx se aproxima dos princípios epistemológicos indicados pelas $\mathrm{OCN}$, referentes ao estranhamento e desnaturalização da realidade social. Sendo assim, divergimos do que é apontado por Souza (2013), que indica um predomínio da matriz weberiana nas atuais propostas curriculares para a Sociologia, presentes nos documentos oficiais e nos materiais didáticos, que ficaria evidente ao analisarmos os princípios do estranhamento e da desnaturalização.

Por outro lado, Durkheim $(1999,2002)$ assume a explicação sociológica como distinta daquela existente no senso comum, bem como na psicologia, afirmando a Sociologia como a ciência que estuda os fatos sociais, e, enquanto tais, possuem uma existência exterior aos indivíduos, mais que isso, podemos compreender que a elaboração que ele realiza para a explicação da realidade social, ao indicar, por exemplo, que a Sociedade é como um organismo, indica possibilidades de análise da realidade social, enquanto universo a ser explorado cientificamente, por meio de metáforas com outras realidades conhecidas.

No que diz respeito a Weber $(1999,2001)$, além da busca por uma síntese original entre explicação e compreensão, podemos destacar sua discussão acerca da distinçáo entre ciência e política dentro dos pressupostos da neutralidade axiológica, que nos remete à necessidade de buscarmos a elaboração de uma didática das Ciências Sociais nos seus próprios fundamentos epistemológicos (CAMILLONI, 2007).

Não se trata aqui de realizar um longo apanhado acerca da contribuição teórica e metodológica dos clássicos da Sociologia para o Ensino dessa ciência na Educação Básica, considerando tanto os limites desse trabalho quanto o foco que nos propomos a desenvolver, assumindo como fio condutor a teoria de Giddens (2005, p. 22), todavia, 
faz-se necessário o reconhecimento da substancial contribuição desses autores, considerando ainda que "[...] os escritos de Marx podem ser comparados aos de Durkheim e aos de Weber, como formas contrastantes de teoria social”.

O reconhecimento da relevância dos clássicos, enquanto partes constitutivas dos "conteúdos" a serem lecionados em Sociologia, está inscrito na presença destes tanto nas Diretrizes Curriculares Estaduais, considerando o atual cenário em que não há um currículo nacionalmente estabelecido (OLIVEIRA, 2013a), bem como nos livros didáticos, todavia pouco ainda se explorou sobre suas contribuiçóes metodológicas. Afirmamos aqui que eles não apenas nos fornecem explicações sobre o mundo, como também formas de produzir explicaçóes, que podem contribuir para o enfrentamento dos desafios encontrados em sala de aula no exercício de lecionar Sociologia na escola.

\section{Problemas de caráter ontológicos ao Ensino de Sociologia: o desafio teórico}

Ao problematizarmos o Ensino de Sociologia não podemos nos furtar de uma reflexão sobre a natureza desta ciência social, pois a Sociologia demanda uma compreensão sobre o próprio fazer sociológico, e, principalmente, sobre a explicação da ciência sociológica e sua especificidade.

Ao nos situarmos no campo da explicação científica devemos considerar as colocaçóes de Popper (2010), que assinala que a ciência explica aquilo que se conhece pelo que é desconhecido, no caso das chamadas Ciências da Natureza isso parece mais claro, contudo, nas Ciências Sociais isso toma outros contornos, afinal, buscamos explicar um mundo já explicado (GIDDENS, 1991). Em verdade, reside aí o nosso grande desafio em termos teóricos, ao menos num movimento de aproximação inicial com a questáo. Como nos aponta Berger (1972), a descoberta em Sociologia, ao contrário das Ciências Naturais, não consiste em descobrir um novo fenômeno até entáo desconhecido, mas na construçáo de uma nova percepção sobre fenômenos que julgávamos conhecer completamente.

Segundo Giddens (1978), a Sociologia possui um caráter de dupla hermenêutica, que se baseia no fluxo de máo dupla entre os conceitos e ideias produzidos pelo saber especializado das Ciências Sociais e aqueles veiculados pelos atores leigos, o que implica dizer também que o saber produzido pelo sistema perito ${ }^{8} \mathrm{da}$ Sociologia possui um impacto sobre a prática dos sujeitos, prática esta que é objeto de investigação da própria Sociologia, tanto com relação a suas consequências intencionais quanto não-intencionais. 
Consoante ao sociólogo britânico, ainda que seja o objeto de investigação da Sociologia a ação social, devemos considerar que, obviamente, os sujeitos sabem o que estáo fazendo, por mais que no mundo social haja uma complexa cadeia de eventos movida, por vezes, pelas consequências não intencionais da ação. O que significa dizer que a Sociologia se centra na explicação acerca de algo que os sujeitos já possuem uma explicaçáo para tanto, contudo, isso náo implica numa reduçáo da Sociologia em uma simples elucidação sobre o que os sujeitos pensam sobre o mundo societário.

Esta redução não seria possível principalmente por duas razóes dentro da teoria de Giddens (1978, 1989, 1991). Primeiramente pela distinção entre a consciência prática e a consciência discursiva, de modo que, por mais haja um fluxo estabelecido entre o senso comum e a própria Sociologia, halita a Sociologia a se situar numa posição de esclarecedora ante ao senso comum. Isso não se daria a partir de uma ruptura epistemológica - como advoga Bourdieu (1974) ao longo de sua obra9 ${ }^{\text {-, }}$ mas sim através de uma explicação discursiva de dimensôes da motivação, cognição e conduta dos atores que operam em nível tácito ou prático.

Para elucidar melhor este ponto necessitamos distinguir a consciência prática da consciência discursiva. Para Giddens (1989), os sujeitos possuem um repertório subjetivo de conhecimentos e crenças tácito, que eles acionam em sua vida cotidiana, ou seja, a consciência prática aproxima-se do conceito de habitus de Bourdieu (2009) ${ }^{10}$, no sentido em que direciona a ação do sujeito. Por outro lado, a consciência discursiva refere-se a um conjunto de conhecimentos que os sujeitos são capazes de expressar discursivamente, se inquiridos a fazê-lo. Portanto, a Sociologia, representa um conhecimento acerca da realidade social, que vai para além da percepçáo presente na consciência prática dos sujeitos, articulando de forma discursiva, através de um experts, que compóem um determinado sistema perito.

Outra questão que nos ajuda a pensar onde a explicação sociológica se situa, diz respeito ao fato de que o sujeito está localizado em meio às circunstâncias e processos, cujo escopo espaço-temporal é muito mais abrangente que a sua biografia pessoal poderia alcançar, tanto pelas condiçôes não-reconhecidas pelo mesmo quanto pelas consequências imprevistas, ou não intencionais, da açáo social, de modo que, ao se debruçar sobre estas questóes a Sociologia apresentaria um papel elucidativo sobre as questóes postas pelo senso comum (GIDDENS, 2001, 2004).

Elucidar acerca destas questôes nos parece fundamental, na medida em que a Sociologia, enquanto disciplina escolar, busca articular tanto os conhecimentos presentes no senso comum, em especial a partir da realidade do aluno, quanto as teorias e categorias sociológicas. Em nossa interpretaçâo, o fazer da Sociologia escolar encontra-se em meio a um duplo movimento, pois de um lado temos o processo de 
reconstrução da realidade nas Ciências Sociais, através de um método específico, em que "O importante, parece, não é o que se 'vê', mas o que se observa com método" (FERNANDES, 2004, p. 126), ou seja, há uma recontextualização dos elementos presentes na consciência prática que os transforma (organiza) através da consciência discursiva, por outro lado, esses elementos devem ser novamente recontextualizados no universo escolar e, principalmente, no universo social, simbólico e cognitivo no qual o aluno se encontra, de modo a tornar a explicação sociológica significativa para o sujeito.

A explicação de um mundo já explicado, nesse sentido, não parece ser uma prática simples, pois o distanciamento primevo com relação ao senso comum, ao buscar a elaboração de uma nova explicação para o já conhecido, precede uma nova aproximação com o mesmo ao recontextualizá-lo na realidade escolar.

Afora este fato, devemos chamar atenção para a assertiva posta por Bourdieu (1974, p. 238), que aponta para uma hierarquização das disciplinas escolares:

A exemplo das distinções entre sexos e faixas etárias, são também diferenças sociais que recobrem as diferenças entre as disciplinas ordenadas segundo uma hierarquia comumente reconhecida: desde as disciplinas mais canônicas, como francês, as letras clássicas, a matemática ou a física, socialmente designadas como as mais importantes e mais nobres (dentre outros indícios, sem virtude do peso nos exames, pelo estatuto de 'professor principal' conferido aos docentes dessas áreas, e, finalmente, pelo consenso dos docentes e dos alunos), até as disciplinas secundárias como a história e a geografia, as línguas vivas (que constituem um caso a parte), as ciências naturais, e as disciplinas marginais, como o desenho, a música e a educação física.

Dessa forma, o caráter de dupla hermenêutica da Sociologia acaba por situá-la numa posiçâo hierárquica mais baixa dentre as disciplinas escolares, se seguirmos esta linha de raciocínio, uma vez que para Bourdieu e Passeron (2008), a escola, em seu processo de exclusão social e cultural, coloca no topo as disciplinas mais teóricas, abstratas, formalizadas que exigem habilidades "não escolares" que só podem ser adquiridas plenamente "fora da escola", e rebaixa as disciplinas que se aproximam mais da realidade do aluno, que podem ser aprendidas através do "esforço".

Nesse sentido, o fato da Sociologia possuir um percurso caudaloso no currículo escolar, marcado por idas e vindas, aprofunda sua posição na hierarquia das disciplinas escolares, contudo, não pode ser encarado como o único elemento explicativo de tal situação, pois, segundo a argumentaçáo exposta, existem elementos constitutivos da Sociologia, que interferem no modo com a disciplina é percebida no universo escolar. 
Temos, portanto, que os desafios postos à Sociologia remetem, também, a seus aspectos ontológicos, de modo que a superação de tais desafios demanda uma articulação teórica entre a Sociologia e a educação, bem como uma delimitação clara dos aspectos teóricos envolvidos na produção do conhecimento sociológico.

Apesar de aproximar-se do senso comum, da realidade empírica do aluno, a Sociologia busca realizar um salto epistemológico (OLIVEIRA, 2011), aproximandose da concepçáo presente em Kant (2012), que concebe que para além da dimensão do fenômeno, captável pelos sentidos, haveria outra, o noumeno, que seria apenas passível de ser pensado. Portanto, a Sociologia, através da consciência discursiva, busca ir além do que se encontra na aparência do que encontramos na realidade social, é desse modo que o seu ensino se articula ao processo de desnaturalização desta realidade, como preconizado nas Orientaçóes Curriculares Nacionais de Sociologia.

\section{Problemas de caráter epistemológico ao Ensino de Sociologia: o desafio metodológico}

Quando refletimos acerca da dimensão do Ensino de uma determinada ciência, novas questôes são postas, pois compreender esta realidade leva também a uma discussão em torno dos dilemas pedagógicos postos. Uma vez que, estando uma dada ciência inserida no currículo como disciplina escolar ela deve considerar que este currículo é resultado da interação entre o campo da contextualização (academia, universidades etc.) de onde são recrutados pelo campo da recontextualização oficial (o Estado, principalmente) para elaborarem documentos, referências etc., e posteriormente são encaminhados para o campo da recontextualizaçáo (escola) onde são novamente elaborados por professores na sua prática pedagógica (BERNSTEIN, 2003), prática essa que não será movida apenas pelo conhecimento acadêmico que determinado professor possui acerca da disciplina que irá lecionar, mas sim por uma gama de saberes docentes que são mobilizados (TARDIFF, 2002), o que se torna ainda mais notório no caso do Ensino de Sociologia na Educação Básica, já que boa parte dos docentes não possuem formação na área. Dessa forma, devemos considerar que:

[...] as práticas de formaçáo de professores de Sociologia nos cursos de Ciências Sociais e nas salas de aula da Educação Básica são capturadas pelo discurso pedagógico predominante e pelas teorias educacionais em disputa nos diferentes momentos da história da educação. Além disso, a formação do professor e das suas práticas na Educação Básica dependem da compreensão de Ciências Sociais/Sociologia da agência formadora, do campo 
das Ciências Sociais e do campo da Educação sobre a pertinência do ensino de Sociologia nas escolas. Essa compreensão é materializada no modo como a Disciplina é ou não inserida nos currículos.

Em suma: a consolidaçấo das Metodologias de Ensino de Sociologia depende por um lado, de fatores ligados à constituiçáo do campo escolar, ou seja, de como o sistema de ensino está organizado e estruturado em termos de condiçóes de trabalho pedagógico e da concepçáo de escola e de currículo e, por outro lado, de fatores ligados à constituição do campo das ciências sociais que informam os conteúdos a serem selecionados no campo escolar. (SILVA, 2009, p. 15).

Tendo em vista tais fatores, temos que compreender que a dinâmica e os desafios postos para o Ensino de Sociologia na Educação Básica nos exigem uma mobilização de recursos para que as aulas desta disciplina não se restrinjam a uma grande digressáo sobre a história da Sociologia e os elementos teóricos que a compóem unicamente; tampouco se coloque como um arrazoado de temáticas do cotidiano do aluno, uma vez que nem tudo que é social é necessariamente sociológico, precisamos ir para além dos dados empíricos, o que "[...] implica em indicar aos alunos as categorias que constroem o mundo social e buscar suas relações, redes de dependência e conexôes teóricas." (FERREIRA; CARNEIRO, 2012, p. 199). Devemos, portanto, articular a realidade vivenciada pelo aluno, pela comunidade na qual a escola está inserida e pelo professor com a teoria sociológica, dado que:

É nesta articulação, entre a realidade e a teoria, que reside a necessidade de se realizar um salto epistemológico, no sentido de tornar as categorias sociológicas palatáveis ao Ensino Médio. $\mathrm{O}$ processo teórico não vale por si mesmo se não possuir um potencial heurístico explicativo sobre a realidade social, a teoria precisa dizer algo sobre a realidade do aluno. Para realizar tal articulaçáo necessitamos da interface realizada pelo senso comum, que é, por excelência, nosso ponto de partida, por mais que náo possa se configurar como nosso ponto de chegada. (OLIVEIRA, 2011, p. 119-120).

Concordamos nesse ponto com o exposto pelas OCN, na medida em que essas destacam a necessidade de articular teorias, conceitos e temas para a realização das aulas de Sociologia, provocando o que seria a finalidade dessa ciência na Educaçáo Básica: o estranhamento e a desnaturalização da realidade social. A este respeito, é válido retornar a Giddens (1978), por compreendermos que a relação entre teoria e senso comum não é 
caracterizada apenas por uma descontinuidade, devendo ser reconhecido que as teorias, podem sim, ser utilizadas recursivamente pelos sujeitos, e, até mesmo, incorporadas em seu vocabulário cotidiano, o que obviamente é um processo gradual. Nesse sentido, nos é válido o exemplo dado pelo sociólogo inglês:

Considere-se... as teorias de soberania formuladas pelos pensadores europeus do século XVII. Elas resultaram da reflexão sobre - e do estudo de - tendências sociais quais foram, por sua vez, realimentadas. É impossível apontar um moderno Estado soberano que náo incorpore uma teoria discursivamente articulada do moderno Estado soberano. [...] A noçáo de soberania e teorias associadas ao estado eram surpreendentemente novas quando foram formuladas pela primeira vez; hoje, tornam-se em certa medida parte integrante da própria realidade social que ajudaram a estabelecer. [...] Por que, agora que estamos familiarizados com o conceito e a realidade da soberania do Estado, as teorias seiscentistas do Estado continuam a ter tanta relevância para a reflexão social ou política hodierna? Por certo, exatamente porque contribuíram para a constituição do mundo social em que vivemos agora. (GIDDENS, 1989, p. XXVII-XXVIII).

O que almejamos com essa discussão não é defender uma "vulgarização do conhecimento sociológico", mas sim destacar que o processo de articular entre as teorias, conceitos e temas na Educaçáo Básica mostra-se complexo, na medida em que lidam com instâncias cujas barreiras não são estanques, muito pelo contrário, no diagnóstico que Giddens (1991) realiza acerca da modernidade, indica-se que há um processo cada vez mais intenso de mobilização reflexiva de conhecimentos acerca do mundo societário na estruturação e reestruturação ativa das características desse mesmo mundo, o que, por si só, apontaria para uma contundente justificativa sociológica para a presença da Sociologia na Educação Básica, inclusive considerando o próprio caráter reflexivo da mesma (OLIVEIRA, 2010).

Ao considerarmos os elementos contingenciais envolvidos na prática pedagógica, que dizem respeito principalmente à formaçấo dos professores, suas condiçóes de trabalho e à própria realidade social e cultural dos demais agentes envolvidos nesta prática, em especial os alunos e suas famílias, esta questão se torna ainda mais complexa.

Pesquisas como a de Lennert (2009) apontam para as condiçóes de trabalho dos professores de Sociologia, que devido à reduzida carga horária da disciplina demanda que estes assumam muitas turmas, por vezes em várias escolas. Ainda segundo a autora: 
A pesquisa encontrou um professor que é contratado temporariamente há cinco anos, dois, há dez anos e dois, há mais de vinte anos. Segundo Sennett (2000), a instabilidade ligada ao trabalho corrói os laços de solidariedade social e traz riscos para as trajetórias pessoais e profissionais (pela ausência da noçáo de futuro, de previsibilidade); os professores não conseguem trabalhar com outros professores, nem pensar em projetos pedagógicos de médio e longo prazo. Mesmo que os professores afirmem que suas extensas jornadas de trabalho e os baixos salários limitem a qualificaçáo e o aperfeiçoamento profissional, a pesquisa encontrou quase $1 / 3$ de professores com cursos de pós-graduaçáo. O aperfeiçoamento e a qualificação, assim como a realização de outros cursos superiores, evidenciam estratégias individuais para a manutenção do emprego. As relaçóes de trabalho marcadas por intensa competiçáo, vivenciada principalmente no processo de atribuição de aulas, não só rompem com os laços de solidariedade como possibilitam a construçáo dessas estratégias não coletivas para fazer face às condiçóes de trabalho. (LENNERT, 2009, p. 99-100).

Tais questôes, que também vêm à tona nas pesquisas de Coan (2006) e Pavei (2008), o que não pode ser compreendido como algo menor dentro do debate sobre os desafios postos para o Ensino da Sociologia, ainda que a precarizaçáo do trabalho docente seja exclusividade dos professores de Sociologia, contudo alguns outros fatores agravam o cenário para aqueles que lecionam essa ciência na Educação Básica, dentre os quais destacaríamos: a) a ausência de uma tradição solidificada da disciplina no currículo escolar; b) via de regra a disciplina conta com apenas uma hora aula semanal na carga horária das escolas de ensino médio; c) presença de uma maioria absoluta de profissionais sem formação específica em Ciências Sociais lecionando a disciplina ${ }^{11}$; ) ausência de um currículo para a disciplina ${ }^{12}$.

Trouxemos para nossa discussão tais questôes por compreendermos que para se refletir sobre o Ensino de Sociologia náo devemos considerar apenas as questôes que tangenciam o seu debate epistêmico e sobre a natureza sociológica da própria Sociologia (FERNANDES, 1980), pois o ensino de uma determinada ciência é mais que simplesmente a reproduçáo dos seus preceitos teóricos, tampouco seria uma "transposição". Em nosso entender, essa atividade aproxima-se muito mais de uma "tradução", no sentido de pensarmos a construção de uma inteligibilidade de uma linguagem para outra, e para que isso ocorra devemos conhecer bem os ambientes em que tais linguagens (a acadêmica e a escolar) são produzidas e circulam. 
Entretanto, também tecemos críticas às $\mathrm{OCN}$, por entendermos que a questão da pesquisa é central no processo de produção do conhecimento sociológico, como o documento aponta, contudo, considerando os próprios desafios postos para se trabalhar a pesquisa em nível de graduação devemos reconhecer as dificuldades de trabalhar com essa metodologia na Educação Básica (GOMES, 2007). Ainda neste sentido, discordamos da releitura das OCN realizada por Moraes e Guimarães (2010), na qual apontam que muitos professores não trabalham com a pesquisa na sala de aula por concepção ou por formação, uma vez que acreditamos que há outras questôes em jogo, com especial destaque para as condiçôes de trabalho vivenciado pelos docentes da Educação Básica.

Contudo, devemos reconhecer também os avanços trazidos pelas OCN ao dar um caráter mais claro ao Ensino de Sociologia, focando no processo de estranhamento e desnaturalização da realidade social, considerando que a simples utilização do clichê "formar para a cidadania" mostra-se insuficiente não apenas para justificar a existência da disciplina na escola, como também para pensarmos na elaboração de estratégias metodológicas para o ensino desta disciplina, considerando que:

Justificar a sociologia em virtude da formação para a crítica e para a cidadania pressupóe preparar os jovens para "um depois"; eles precisam aprender certos conteúdos para um dia exercer essas condiçóes. E a escola não faz parte da trama social atual? Nela náo se exerce a crítica e a cidadania? Argumentar a importância do conhecimento sociológico segundo aquele horizonte pode negar aos jovens a participação política; protela-se essa possibilidade em vista dos seus "desinteresses, descompromissos, apatias", como frequentemente são caracterizados por professores. (MOTA, 2005, p. 99).

Levantamos tais questôes por reconhecermos que os desafios no nível metodológico se imbricam tanto aos aspectos ontológicos da própria Sociologia como também aos aspectos contingenciais que dizem respeito principalmente às condiçôes sob as quais o ensino é vivenciado. Refletir sobre os desafios metodológicos do ato de ensinar Sociologia deve nos levar a analisar tanto o domínio teórico que o professor possui da ciência de referência ${ }^{13}$ que irá lecionar, bem como das questôes pedagógicas que envolvem a dinâmica do ensino, ambas as questóes encontram-se intimamente relacionadas, como podemos observar a partir da pesquisa realizada por Santos (2002), em que professores com formaçôes diversas tendem a perceber a Sociologia de forma diferenciada no que tange as suas finalidades no Ensino Médio, o que possui implicaçôes também sobre o trabalho que desenvolvem em sala de aula. 
Também podemos encontrar indícios desta questão na pesquisa de Takagi (2007), que verifica a utilização de uma pluralidade maior de recursos didáticos por parte dos licenciandos de Ciências Sociais, comparando-se com os professores atuantes na rede pública de ensino, em sua maioria sem formação específica no campo das Ciências Sociais.

Outro aspecto que deve ser considerado diz respeito aos demais agentes envolvidos na prática educativa, destacando-se nesse âmbito o que Charlot (1996, 2000) denomina de relação com o saber, a qual possui três dimensóes: a epistêmica, a social e a de identidade. A relaçáo epistêmica com o saber parte do fato de que "aprender" não significa a mesma coisa para todos os alunos, essa relação também é social, uma vez que exprime as condições sociais do indivíduo e as relaçóes sociais que estruturam a sociedade na qual este aluno está inserido, e, por fim, esse processo de aprendizado constitui a construção de si mesmo.

Ou seja, para constituirmos um habitus sociológico no universo escolar (HAMLIN, 2009) precisamos considerar não apenas o que o professor realiza em sala de aula, sua formação, sua trajetória docente, suas condiçôes de trabalho, mas também os significados socialmente construídos dentro das trajetórias individuais e familiares de nossos alunos; devemos nos propor uma reflexão mais profunda sobre os sentidos que a escola possui para nossos alunos, sobre os horizontes que ela apresenta e pode apresentar para os mesmos.

Se de fato um dos desafios para a Sociologia é explicar um mundo já explicado, como nos diz Giddens (1991), o nosso desafio inicia-se, portanto, no conhecimento da consciência prática de nossos alunos, na tarefa de buscar ter acesso às formas como estes compreendem e explicam o mundo social, para que possamos pensar numa forma de elaboração explicativa nos termos da ciência discursiva. Notoriamente, possuir uma consciência prática, de modo a agir no mundo social, não implica na capacidade automática de explicar discursivamente esta realidade, o que nos remete à assertiva de Velho (1994), segundo o qual nem tudo que nos é familiar é conhecido, e por isso mesmo a capacidade de provocar o estranhamento, como preconiza as OCN, mostra-se fundamental para o Ensino de Sociologia, pois é por meio deste que conseguiremos provocar a elaboração de uma explicação discursiva para um fenômeno que já é conhecido em termos de prática.

\section{Considerações Finais}

Este breve trabalho buscou elucidar acerca de algumas questôes postas ao Ensino de Sociologia na Educação Básica, considerando que para compreendermos 
essas questốes para o Ensino dessa ciência devemos levar em conta tanto os aspectos que dizem respeito à produção do Pensamento Sociológico - ou seja, o que é pensar sociologicamente; como se dá a descoberta sociológica; o que a Sociologia produz em termos de conhecimento; como produz - como também devemos ter em vista os aspectos contingenciais postos ao Ensino da Sociologia, alguns bastante gerais dentro da realidade escolar brasileira, outros específicos de uma disciplina que só recentemente voltou a figurar na Educação Básica, ainda assim sob condiçôes precárias.

Ao nos utilizarmos da categoria de dupla hermenêutica trazida por Giddens, que percebe a Sociologia num movimento contínuo com relação ao senso comum, incorremos tanto na possibilidade de termos nossas aulas facilitadas pela aproximação do conhecimento escolar com a realidade do aluno como também de simplesmente não darmos um tratamento científico do conhecimento trabalhado em sala de aula, o que seria um equívoco, já que o conhecimento escolar possui uma especificidade com relação ao conhecimento não escolar (YOUNG, 2007).

Ao final desse trabalho fica-nos evidente a necessidade de buscarmos na Sociologia os fundamentos pedagógicos necessários para subsidiar a prática dos professores que lecionam essa ciência na escola, ainda que isso náo implique em esquecermos a relevância de todo o acúmulo de discussóes que têm sido realizadas no campo educacional, no sentido mais estrito. A aproximação com o senso comum, com o conhecimento que o aluno já possui sobre o mundo social deve ser interpretada, ao recorrermos à discussão sociológica, como uma ampliação das possibilidades didáticas da Sociologia, mas também como um desafio, que deve levar os professores a desenvolverem uma verdadeira "vigilância epistemológica" do seu fazer profissional. Somada a estas questóes, deve-se encarar a necessidade de se pensar os limites e possibilidades postos pelo ensino de Sociologia frente às condiçốes objetivas nas quais se realiza o fazer pedagógico, dada a impossibilidade de realização de uma transposição automática do saber produzido nas universidades para a sala de aula, bem como os demais elementos contingenciais existentes na Educação Básica. Estas são apenas algumas questốes postas, e considerando que ainda se trata de uma temática incipiente em termos de pesquisas, acreditamos que ainda há um vasto campo por desbravar para uma melhor compreensão dos desafios postos ao Ensino de Sociologia, o que engloba questóes tão diversas relacionadas ao currículo, à formação de professores, à elaboração de materiais didáticos etc. 


\section{Notas}

${ }^{1}$ Isto pode ser verificado tanto pelo incremento de pesquisas em nível de pósgraduação quanto pela abertura de espaços para a discussão da temática, destacando-se a abertura do GT Ensino de Sociologia, junto com Congresso Brasileiro de Sociologia em 2005, a criação do Encontro Nacional sobre Sociologia na Educação Básica em 2009, e a fundação da Associação Brasileira de Ensino de Ciências Sociais em 2012.

${ }^{2}$ No Brasil, o ensino de Sociologia só é obrigatório atualmente em nível nacional no Ensino Médio há, contudo, experiências pontuais do ensino desta ciência no Ensino Fundamental, como no caso do Estado do Pará, bem como em algumas escolas de forma pontual, como no caso do Colégio Pedro II no Rio de Janeiro.

${ }^{3}$ Vide trabalhos de Santos (2002), Silva (2010), Moraes (2011) e Oliveira (2013b).

${ }^{4}$ É por meio do Decreto no 16.782-A, de 13 de janeiro de 1925 (Reforma Rocha Vaz), que a Sociologia passa a figurar no currículo nacional, todavia, deve-se reconhecer os limites introduzidos por este ato normativo, uma vez que as reformas neste período só tinham um impacto direto sobre o distrito federal, em termos de currículo, para ser mais preciso, sobre o Colégio Pedro II, que servia de modelo para as demais escolas. Em todo o caso, deve-se destacar que já em 1892 no Atheneu Sergipense figurava a disciplina intitulada "sociologia, moral, noçóes de economia política e direito pátrio" (ALVES; COSTA, 2006).

${ }^{5}$ Para uma melhor análise do histórico da Sociologia enquanto disciplina escolar vide os trabalhos de Guelfi (2001), Santos (2004), Silva (2010), Moraes (2011).

6 Para ser mais preciso a Reforma Capanema extingue os cursos complementares, nos quais a Sociologia estava alocada, de modo que não foi um ataque específico à disciplina de Sociologia, como alguns autores deixam a entender ao relatar o histórico da disciplina na Educação Básica. Moraes (2011, p. 365) chega mesmo a afirmar que: "[...] entendemos que a exclusão da Sociologia do currículo prende-se menos a preconceitos ideológicos e mais à indefinição do papel dessa disciplina no contexto de uma formação que se definia mais orgânica, resultado do estabelecimento de uma burocracia mais técnica e mais exigente ou convicta em relação à concepçáo de educação. De certa forma, pode-se dizer que os defensores da Sociologia não conseguiram convencer essa burocracia educacional quanto à necessidade de sua presença nos currículos". 
7 Para uma melhor análise acerca do processo de tramitação no congresso do projeto de lei que visava a reintrodução da Sociologia na Educação Básica, vetado em 2001 pelo entáo presidente Fernando Henrique Cardoso, vide Carvalho (2004) e Moraes (2004).

${ }^{8}$ Segundo Giddens (1991, p. 35), "Por sistemas peritos quero me referir a sistemas de excelência técnica ou competência profissional que organizam grandes áreas dos ambientes material e social em que vivemos hoje".

9 Podemos verificar essa postura metodológica de Bourdieu, Passeron e Camboredon (2004) de forma mais acabada na obra O Ofício do Sociólogo.

${ }^{10} \mathrm{O}$ sociólogo francês nos dá a seguinte definição da categoria habitus: "[...] sistemas de disposições duráveis e transponíveis, estruturas estruturadas predispostas a funcionar como estruturas estruturantes, ou seja, como princípios geradores e organizadores de práticas e de representaçôes que podem ser objetivamente adaptadas ao seu objetivo sem supor a intenção consciente de fins e o domínio expresso das operaçôes necessárias para alcança-los, objetivamente 'reguladas' e 'regulares' sem em nada ser o produto da obediência a algumas regras e, sendo tudo isso, coletivamente orquestradas sem ser produto da ação organizadora de um maestro". (BOURDIEU, 2009, p. 87).

${ }^{11}$ Segundo o Censo da Educação (2007), apenas 13,2\% dos professores de Sociologia possuem formação em Ciências Sociais (LENNERT, 2009).

${ }^{12}$ Apesar da ausência de currículo nacional comum, Santos (2012) aponta para uma convergência entre várias diretrizes curriculares nacionais, o que pode ser interpretado como uma forma de "currículo mínimo" que vem sendo seguindo em vários Estados.

${ }^{13}$ Apesar de falarmos de Ensino de Sociologia, é válido ressaltar que a tradição acadêmica brasileira nos remete a uma formaçáo em nível superior no campo das chamadas Ciências Sociais: Sociologia, Antropologia e Ciência Política, náo à toa os Parâmetros Curriculares Nacionais (BRASIL, 1999) fazem referência a estas três ciências. Mais recentemente o edital de seleçấo do livro de Sociologia junto ao Plano Nacional do Livro Didático (BRASIL, 2011) indicava como um dos critérios que deveriam ser atendidos era que tal material abarcasse conteúdos de Sociologia, Antropologia e Ciência Política (BRASIL, 2011). 


\section{REFERÊNCIAS}

ALEXANDER, Jeffrey C. A importância dos Clássicos. In: GIDDENS, Anthony; TURNER, Jonathan (Org.) Teoria Social Hoje. São Paulo: Editora da UNESP, 1999. p. 23-89.

ALVES, Eva Maria Siqueira; COSTA, Patrícia Rosalba Salvador Moura. Aspectos históricos da cadeira de Sociologia nos Estudos Secundários (1892-1925). Revista Brasileira de História da Educação, Maringá, v. 6, n. 2, p. 31-51, 2006.

BARBOSA, Maria Ligia; QUINTANEIRO, Tania; RIVERO, Patrícia. Conhecimento e imaginação sociológica para o Ensino Médio. Belo Horizonte: Autêntica, 2012.

BERGER, Peter. Perspectivas Sociológicas. Petrópolis, RJ: Vozes, 1972.

BERNSTEIN, Basil. A pedagogização do conhecimento: estudos sobre recontextualização. Cadernos de Pesquisa, São Paulo, n. 120, p.75-110, nov. 2003. BOURDIEU, Pierre. A economia das trocas simbólicas. São Paulo: Perspectiva, 1974. BOURDIEU, Pierre; PASSERON, Jean-Claude. A reprodução. Petrópolis, RJ: Vozes, 2008.

BOURDIEU, Pierre. O senso prático. Petrópolis, RJ: Vozes, 2009.

BOURDIEU, Pierre; PASSERON, Jean-Claude; CAMBOREDON, Jean-Claude. O Ofício do Sociólogo: metodologia na pesquisa na sociologia. Petrópolis, RJ: Vozes, 2004.

BRASIL. Lei n ${ }^{\circ}$ 5.692, de 11 de agosto de 1971. Fixa Diretrizes e Bases para o ensino de $1^{\circ} \mathrm{e}$

$2^{\circ}$ graus, e dá outras providências. Diário Oficial da Uniāo, Brasília, DF, 12 ago. 1971.

BRASIL. Parâmetros Curriculares Nacionais. Ministério da Educação: Brasília, 1999.

BRASIL. Orientaçôes Curriculares Nacionais. Ministério da Educação: Brasília, 2006.

BRASIL. Lei n ${ }^{\circ} 11.684$, de 2 de junho de 2008. Altera o art. 36 da Lei no 9.394, de 20 de dezembro de 1996, que estabelece as diretrizes e bases da educação nacional, para incluir a Filosofia e a Sociologia como disciplinas obrigatórias nos currículos do ensino médio. Diário Oficial da União, Brasília, DF, 3 jun. 2008. 
BRASIL. Ministério da Educação. Guia de livros didáticos: PNLD 2012 Sociologia. Brasília: MEC/SEB, 2011.

CAMILLONI, Alicia R. W. Espistemología de la didáctica de las ciencias sociales. In: AISENBERG, Beatriz; ALDEROQUI, Silvia (Org.). Didáctica de las ciencias sociales: aportes y reflexiones. Buenos Aires: Paidós, 2007. p. 25-41.

CANCLINI, Néstor García. Culturas híbridas: estratégias para entrar e sair da modernidade São Paulo: EDUSP, 1997.

CÂNDIDO, Antonio. A sociologia no Brasil. Tempo Social, Sáo Paulo, v. 18, n. 1, p. 271-301, 2006.

CAREGNATO, Célia Elizabete; CORDEIRO, Victoria Carvalho. Campo científico-acadêmico e a disciplina de sociologia na escola. Educação \& Realidade, Porto Alegre, v. 39, n. 1, p. 39-57, jan./mar. 2014.

CARVALHO, Lejeune Mato Grosso de. A trajetória histórica da luta pela introdução da disciplina de sociologia no Ensino Médio no Brasil. In: CARVALHO, Lejeune Mato Grosso de (Org.). Sociologia e ensino em debate: experiências e discussão de sociologia no ensino médio. Ijuí: Ed. Unijuí, 2004. p. 17-60.

CHARLOT, Bernard. Relação com o saber e com a escola entre estudantes de periferia. Cadernos de Pesquisa, São Paulo, n. 97, p. 47-63, maio 1996.

CHARLOT, Bernard. Da relação com o saber: elementos para uma teoria. Porto Alegre: Artmed, 2000.

COAN, Marival. A Sociologia o ensino médio, o material didático e a categoria trabalho. 2006. 356 f. Dissertação (Mestrado em Educação) - Universidade Federal de Santa Catarina, Florianópolis, SC, 2006.

DURKHEIM, Émile. As regras do método sociológico. São Paulo: Companhia Editora Nacional, 2002.

DURKHEIM, Émile. Da divisão do trabalho social. São Paulo: Martins Fontes, 1999.

FAORO, Raimundo. Os donos do poder. Rio de Janeiro: Globo, 2001.

FERNANDES, Florestan. A natureza sociológica da sociologia. São Paulo: Ática, 1980 .

FERNANDES, Florestan. Sociologia critica e militante. São Paulo: Expressão Popular, 2004. 
FERREIRA, Fátima Ivone de Oliveira; CARNEIRO, Silzane de Almeida. Nem tudo que é social é sociológico: sociologia e senso comum na escola básica. In: HANDFAS, Anita; MAÇAIRA, Julia Polessa (Org.). Dilemas e perspectivas da sociologia na educação básica. Rio de Janeiro: E-Papers, 2012. p. 195-204. GIDDENS, Anthony. Novas regras do método sociológico. Rio de Janeiro: Zahar, 1978 .

GIDDENS, Anthony. A constituição da sociedade. São Paulo: Martins Fontes, 1989. GIDDENS, Anthony. As consequências da modernidade. São Paulo: Editora da UNESP, 1991.

GIDDENS, Anthony. Em defesa da sociologia. São Paulo: Editora da UNESP, 2001. GIDDENS, Anthony. Sociologia. Porto Alegre: Artmed, 2004.

GIDDENS, Anthony. Capitalismo e moderna teoria social. Lisboa: Editoral Presença, 2005.

GOMES, Ana Laudelina F. Notas críticas sobre as Orientações Curriculares Nacionais para a Sociologia no Ensino Médio. Cronos, Natal, RN, v. 8, n. 2, p. 475486, jul./dez. 2007.

GUELFI, Wanirley Pedroso. A Sociologia como disciplina escolar no Ensino Secundário brasileiro (1925-1942). 2001. 194 f. Dissertação (Mestrado em Educação) Universidade Federal do Paraná, Curitiba, 2001.

HAMLIN, Cynthia Lins. Desenvolvendo uma Terceira Cultura nas Escolas: habitus sociológico, estranhamento e desnaturalização de preconceitos. Tomo, São Cristóvão, SE, , n. 15, p. 71-82, 2010.

HANDFAS, Anita. O estado da arte do ensino de sociologia na educação básica: levantamento preliminar da produçáo acadêmica. Inter-legere, Natal, RN, n. 9, p. 386-400, 2011.

KANT, Immanuel. Crítica da razão pura. Petrópolis, RJ: Vozes, 2012.

LENNERT, Ana Lucia. Professores de Sociologia: relaçóes e condiçóes de trabalho. 2009. 108 f. Dissertação (Mestrado em Educação). Universidade Estadual de Campinas, Campinas, SP, 2009.

MARX, Karl. O Capital: crítica da economia política. Rio de Janeiro: Civilização Brasileira, 2008. 
MEUCCI, Simone. Institucionalização da sociologia no Brasil: primeiros manuais e cursos. São Paulo: Hucitec; Fapesp, 2011.

MORAES, Amaury Cesar. O Veto de FHC: o sentido de um gesto. In: CARVALHO, Lejeune Mato Grosso de (Org.). Sociologia e ensino em debate: experiências e discussão de sociologia no ensino médio. Ijuí: Ed. Unijuí, 2004. p. 105-111.

MORAES, Amaury Cesar; GUIMARÁES, E. F. Metodologia de Ensino de Ciências Sociais: relendo as OCEM-Sociologia. In: MORAES, Amaury Cesar (Org.). Explorando o Ensino de Sociologia. Brasília: MEC/SEB, 2010. p. 45-62.

MORAES, Amaury Cesar. Ensino de Sociologia: periodização e campanha pela obrigatoriedade. Cadernos CEDES, Campinas, SP, v. 31, n. 85, p. 359-382, 2011. MOTA, Kelly Cristine Corrêa da Silva. Os lugares da sociologia na formaçáo de estudantes do ensino médio: as perspectivas de professores. Revista Brasileira de Educação, Rio de Janeiro, n. 29, p. 88-107. 2005.

OLIVEIRA, Amurabi Pereira de. Sociologia do Ensino de Sociologia no Brasil: contribuiçôes a partir de Anthony Giddens. Inter-ação, Goiânia, v. 35, n. 1, p. 5362, 2010.

OLIVEIRA, Amurabi Pereira de. Ensino de Sociologia: desafios epistemológicos para o ensino médio. Revista Espaço Acadêmico, Maringá, PR, ano 10, n. 119, p. 115-121, abr. 2011.

OLIVEIRA, Amurabi Pereira de. O Currículo de Sociologia na escola: um campo em construção (e disputa). Revista Espaço do Currículo, João Pessoa, v. 6, n. 2, p. 355-366, 2013 a.

OLIVEIRA, Amurabi Pereira de. Revisitando a história do ensino de sociologia na educação básica. Acta Scientiarum, Maringá, PR, v. 35, n. 2, 2013 b.

OLIVEIRA, Amurabi Pereira de. Ensino de Sociologia: novas temáticas e experiências internacionais. Educação \& Realidade, Porto Alegre, v. 39, n. 1, p. 1116, jan./mar. 2014.

PAVEI, Katiuci. Reflexóes sobre o ensino e a formação de professores de sociologia. 2008. Dissertação de Mestrado (Mestrado em Educação) - Universidade Federal do Rio Grande do Sul, Porto Alegre. 2008.

POPPER, Karl Raimund. Karl Popper: textos escolhidos. Rio de Janeiro: Contraponto, 2010. 
RIBEIRO, Adélia Maria Miglievich et al. Sociologia e Filosofia nas escolas de ensino médio: ausências, permanências e perspectivas. In: HANDFAS, Anita; OLIVEIRA, Luiz Fernandes (Org.). A Sociologia vai à Escola: história, ensino e docência. Rio de Janeiro: Quartet; FAPERJ, 2009. p. 49-59.

SANTOS, Mário Bispo dos. A sociologia do ensino médio: o que pensam os professores da rede pública de ensino do Distrito Federal. 2002. Dissertação de Mestrado (Mestrado em Sociologia) - Universidade de Brasília, Brasília. 2002.

SANTOS, Mário Bispo dos. A Sociologia no contexto das reformas do Ensino Médio. In: CARVALHO, Lejeune Mato Grosso de (Org.). Sociologia e ensino em debate: experiências e discussão de sociologia no ensino médio. Ijuí: Editora da Unijuí, 2004. p. 131-180.

SANTOS, Mário Bispo dos. Diretrizes Curriculares Estaduais para o Ensino de Sociologia: em busca do mapa comum. Percursos, Florianópolis, SC, v. 13, n. 1, p. 159, 2012.

SARANDY, Flávio. A Sociologia volta à Escola: um estudo dos manuais de sociologia para o ensino médio no Brasil. 2004. 142 f. Dissertação (Mestrado em Sociologia e Antropologia) - Universidade Federal do Rio de Janeiro, Rio de Janeiro, 2004.

SAVIANI, Dermeval. Escola e Democracia. Campinas: Autores Associados, 2009.

SILVA, Ileizi L. F. A Sociologia no ensino médio: desafios institucionais e epistemológicos para a consolidaçáo da disciplina. Cronos, Natal, RN, v. 8, n. 2, p. 403-427, jul./dez. 2007.

SILVA, Ileizi L. F. Metodologias do Ensino e Sociologia na Educação

Básica:aproximaçôes com os Fundamentos Pedagógicos.. In: SILVA, Ileizi L. F. et al. (Org.). Caderno de Metodologias de Ensino e de Pesquisa de Sociologia. Londrina: SETI-PR, 2009, p. 15-35.

SILVA, Ileizi L. F. O Ensino das Ciências Sociais/Sociologia no Brasil: histórico e perspectivas. In: MORAES, Amaury Cesar de (Org.). Coleção Explorando o Ensino de Sociologia. Brasília: MEC, 2010. p. 23-31.

SOUZA, Davisson Charles C. O ensino de Sociologia e a Pedagogia HistóricoCrítica: uma análise dos fundamentos teórico-metodológicos das propostas atuais. Revista HISTEDBR, Campinas, SP, v. 13, n. 51, p. 122-138, 2013.

SOUZA, Shelley. A defesa da disciplina Sociologia nas politicas para o ensino médio de 1996 a 2007. 2008. 87 f. Dissertação (Mestrado em Educação) - Universidade Federal do Rio de Janeiro, Rio de Janeiro, 2008. 
TAKAGI, Cassiane. Ensinar Sociologia: análise de recursos de ensino no ensino na escola média. 2007. Dissertação (Mestrado em Educação) - Universidade de São Paulo, São Paulo, 2007.

TARDIF, Maurice. Saberes docentes e formação profissional. Rio de Janeiro: Vozes, 2002.

VANDENBERGHE, Frédéric. Uma história filosófica da sociologia alemã: alienação e reificação. São Paulo: Annablume, 2012. v. 1.

VELHO, Gilberto. Individualismo e cultura. Rio de Janeiro: Jorge Zahar Editor, 1994.

WEBER, Max. Economia e Sociedade. Brasília: Editora da UNB, 1999. v. 1.

WEBER, Max. Ciência e política: duas vocaçôes. São Paulo: Martin Claret, 2001.

YOUNG, Michael. Para que servem as escolas? Educação\& Sociedade, Campinas, SP, v. 28, n. 101, p. 1287-1302, set./dez. 2007. 


\section{T h e o r e t i c a l a n d methodological challenges of teaching sociology in high school}

\begin{abstract}
With the process of reintroduction of Sociology in Basic Education in 2008 much has been debated about the teaching of this science in schools. However, due to the very absence of a tradition of sociology in the school curriculum, the discussion is still incipient and limited to a small community of researchers. One of the relevant issues that emerge on this new picture is what are the challenges in the teaching practice for the teacher of Sociology. Thus, we aim to contribute to this discussion through an articulate reflection on two levels: the first refers to the theoretical challenges, the second to the methodological challenges of teaching Sociology. For this purpose we used mainly the work of Giddens to understand the relationship between sociological knowledge and common sense, question which in our view is of utmost relevance for the Teaching of Sociology within school reality. In this paper we draw attention to the fact that the proximity to common sense opens up a field of possibilities, but also constitutes a challenge for the teacher, considering the "double hermeneutic" sociology, which is present in both theoretical and methodological levels.
\end{abstract}

Keywords: Teaching of Sociology. Teaching Practice. Methodology of Teaching.

\section{Los desafíos teóricos y metodológicos de la Enseñanza de Sociología en la Escuela Secundaria}

\section{Resumen}

Con el proceso de reintroducción de la Sociología en la Educación Básica en 2008, mucho se ha discutido sobre la enseńanza de esta ciencia en las escuelas. Sin embargo, debido a la ausencia de una tradición de la sociología en el currículo escolar, la discusión es aún incipiente y limitada a una pequeña comunidad de investigadores. Uno de los temas importantes que surgen en este nuevo escenario es sobre los desafíos para la enseñanza del profesor de Sociología, en este sentido, se pretende contribuir en este debate mediante una reflexión articulada en dos niveles: el primero se refiere a los desafíos teóricos, el segundo es sobre los desafíos metodológicos de la Enseńanza de Sociología. Para tanto, se utiliza principalmente la obra de Giddens para entender la relación entre el conocimiento sociológico y el sentido común, que en nuestra opinión es de suma importancia para la Enseñanza de Sociología en la realidad escolar. En este trabajo llama la atención sobre el hecho de que la proximidad con el sentido común abre un campo de posibilidades, pero también representa un desafío para los profesores, teniendo en cuenta la "doble hermenéutica" de la sociología, que se presenta tanto a nivel teórico como metodológico.

Palabras Claves: Enseñanza de la Sociología. Práctica Educativa. Metodología de la Enseñanza. 


\section{Amurabi Pereira de Oliveira}

E-mail: amurabi_cs@hotmail.com

Recebido em: 22/6/2013 Aprovado em: 8/4/2014 